\title{
Living In-Between or Within? Cultural Identity Profiles of Second-Generation Young Adults with Immigrant Background
}

\section{Stephanie Barros \& Isabelle Albert}

To cite this article: Stephanie Barros \& Isabelle Albert (2020) Living In-Between or Within? Cultural Identity Profiles of Second-Generation Young Adults with Immigrant Background, Identity, 20:4, 290-305, DOI: 10.1080/15283488.2020.1832491

To link to this article: https://doi.org/10.1080/15283488.2020.1832491

曲 Published online: 08 Nov 2020.

Submit your article to this journal $๘$

Џ Article views: 30

Q View related articles 5

View Crossmark data \lceil 


\title{
Living In-Between or Within? Cultural Identity Profiles of Second-Generation Young Adults with Immigrant Background
}

\author{
Stephanie Barros iD $^{\mathrm{a}}$ and Isabelle Albert ${ }^{\mathrm{a}}$ \\ aDepartment of Behavioural and Cognitive Sciences, University of Luxembourg, Luxembourg, Luxembourg
}

\begin{abstract}
Migration flows have generally led to an increase in questions about the multiple influences on people's cultural identity. This study aims to examine more closely the ways in which second-generation individuals of Portuguese descent juggle a two-fold cultural environment. We opted for a personcentered approach with a sample of $\mathrm{N}=70$ adults, all from Portuguese immigrant families living in the Grand-duchy of Luxembourg. Results yielded three different bicultural profiles: blended, alternating bicultural, and a new ambivalent cultural identity profile. Our results distinguish between psychological markers of identity and the behavioral aspects necessary for the transition from one cultural framework to the other. In addition, we observed different patterns of psychosocial health among the four cultural identity profiles. Our research enriches the literature by highlighting different endorsement of regulatory control strategies of second-generation adults according to their cultural identity profile, with different psychological outcomes.
\end{abstract}

\section{KEYWORDS}

Bicultural identity; migration; regulatory strategies; psychological outcomes; second generation

\section{Introduction}

"It's normal to be like me, a bit of this and a bit of that, it's a mixture"

[Joana, 28; IRMA project, 2013-2016 ${ }^{1}$ ]

Cultural mixing has become a common feature of many societies today, and an increasing number of residents experience multiple cultural influences on their identities (Barros \& Albert, 2020). Although several studies have described the bicultural identity configurations of the second generation in immigrant families, little is still known about how individuals actually negotiate and combine the different elements of their double cultural identities in multicultural contexts such as the GrandDuchy of Luxembourg. In addition, managing multiple cultural identities appears to be strongly related to opportunities and/or constraints in the pursuit of life goals (West et al., 2017). During acculturation, it is important to adapt to culturally specific contexts in order to maximize psychological outcomes during cultural contact. Individuals in a double cultural context are thus likely to use different regulatory strategies according to their goals and motivations while trying to obtain the best psychological outcomes.

Thus, based on previous research (Barros \& Albert, 2020), our current study focuses on secondgeneration young adults of Portuguese immigrant origin who were born or raised in Luxembourg, a multicultural society nested in the heart of Europe. In particular, the aim is to explore their negotiation of double cultural affiliations. In January 2020, Luxembourg's population was comprised of $47.4 \%$ foreign residents, of a total Luxembourg resident population of $626^{\circ} 108$ (Statec, 2020). Luxembourg then counted $95^{\circ} 100$ residents of Portuguese immigrant origin (i.e., holders of Portuguese passports; 15.2\%), making them the largest cultural group of immigrants in 